\title{
A Coaching Program for Recently Licensed Young Drivers in the Netherlands: Which Drivers Are
} \section{Attracted?}

\author{
Erik C. Roelofs ${ }^{1}$, Jan A.M.M. Vissers ${ }^{2}$ and Marieke J.H. van Onna ${ }^{1}$ \\ 1. Measurement and Research Department, Cito, Arnhem 1034, the Netherlands \\ 2. Unit Transport, Royal HaskoningDHV, Amersfoort 1132, the Netherlands
}

\begin{abstract}
In line with European developments, a Dutch second phase coaching program, referred to as the DX- (Driver Xperience) program, was developed for young novice drivers to counteract their high accident risk. More specifically, the aim of the DX-program was to enable young drivers to make responsible decisions and develop positive attitudes regarding four levels of the driving task: combining life style and driving, planning and navigation, participating in different traffic situations and handling the vehicle. In this paper, the design principles of the program are described. The empirical study focused on the entry characteristics of the participating young drivers $(n=3,117)$ as compared to a reference group of young drivers $(n=345)$. Results show that the DX-program attracted young drivers that, in some respects, showed a more risky profile than average young drivers in terms of speed violations, anger and the number of fines. In addition, four groups of participants with sharply differing driving styles could be distinguished. Implications for educational design and follow-up research are discussed within the theoretical framework of self-regulated learning.
\end{abstract}

Key words: Coaching, young drivers, group heterogeneity, driving style, self-regulated learning, learning motivation.

\section{Introduction}

\subsection{Second Phase Driver Training}

In order to counteract the high accident risk of young novice drivers during their first year of solo driving, several European countries have introduced so-called second phase training programs, aimed at young drivers who have recently acquired their driving license. It has been emphasized that these programs should concentrate on driving style variables, i.e., the way that young people choose to drive [1]. Helman et al. [2] mention style variables that are associated with collision risk: speed choice, close following, high-risk overtaking, violation of traffic laws, driving anger and engaging in distracting activities, such as texting and phoning. Also, factors

Corresponding author: Erik C. Roelofs, Ph.D., research fields: assessment, teaching and driver training. E-mail: Erik.Roelofs@cito.nl. located on the lifestyle level appear to be associated with collision risk: fatigue-related factors, alcohol use, overconfidence, sensation seeking and boredom. The readiness and ability to take these factors into consideration when driving require higher order skills, such as self-reflection and awareness of emotions [3, 4]. Recent studies show that dedicated training aimed at these higher order skills does counteract the factors that cause young drivers' crash involvement [5-8].

Regarding the preferable approach, it is stressed that higher order skills development should involve forms of driver coaching. According to recent insights [9], driver coaching puts learners in an active role, encourages learners to accomplish personal goals, and raises awareness and responsibility of learners regarding their values, attitudes, knowledge, skills and habits. Coaching is expected to stimulate a sustainable learning process by supporting cognitive and affective self-regulation on the part of the learner [10]. 
However, a challenge for the coaches is to deal with differences in learner entry characteristics that are predictive for subsequent learning: prior knowledge, cognitive abilities, past performance, degree of self-regulation and motivation $[11,12]$. From research on teaching, it is known that group heterogeneity is one of the most challenging factors for teachers to deal with. In general, it takes at least five years for licensed teachers to reach a level of expertise to be able to gear their instruction and coaching to individual students [13]. Generally speaking, driving instructor preparation is shorter and less far-reaching than teacher training [14]. However, driver coaches have to deal with differences in driver (learner) entry characteristics, which are similar to the differences faced by elementary school teachers. This study aims to shed some light on the entry characteristics of recently young licensed drivers who have chosen to participate in the DX-program (Driving Xperience program).

In addition to the driving style variables as mentioned above, the study includes young drivers' motivation to participate. In school settings, it is generally found that learners who participate in learning activities on the basis of intrinsic motivation or on internalized forms of extrinsic motivation, referred to as "identified regulation" use stronger self-regulation strategies during the learning process than learners with unclear motives ("amotivation") or extrinsic motives [15]. These very strategies (goal setting, planning, monitoring progress and self-evaluation) tend to contribute to active involvement in learning processes and subsequent positive learning outcomes [16-18].

\subsection{The Dutch Second Phase Coaching Program "Drive Xperience"}

The current study focused on a Dutch second phase coaching program, the "DX" (Drive Xperience), developed as part of a EU-project on the evaluation of post-license training for novice drivers [19]. The
DX-program was introduced parallel to post-license training programs in five other European countries in 2003. It was funded by the Regional Agency for Traffic Safety in the province of Gelderland in the Netherlands.

Since 2003, the DX-program has attracted about 2,000 young drivers per year. This number of participants cannot be exceeded because of a limited available budget. As opposed to other European countries, participation in the program is voluntary. The cost per participant amounts to approximately $€ 150$. This amount does not include costs for the training venue, communication with participants and for cars used on the track. These extra costs were covered by the municipality and the local companies in the city where the coaching day took place.

Participants were recruited in two steps. As a first step, representatives from municipality councils, aldermen responsible for traffic design and safety, were contacted two or three months before the actual coaching day in order to get consent for hosting the program and the bearing of additional costs. Relatively big municipalities, with about 200,000 inhabitants hosted up to eight coaching days, serving about 280 recently licensed young drivers, whereas small municipalities (about 30,000 inhabitants) hosted one or two coaching days serving 70 young drivers. The second step took place after support from the municipality was acquired. The actual recruitment of young drivers took place by means of advertisements in local newspapers, announcements on Facebook and by means of announcements on the website of the DriveXperience organization. The construction of these tools was financially supported by the Regional Agency for Traffic Safety in the province of Gelderland. In some municipalities, participants received a personal invitation letter, signed by the mayor.

The actual coaching day took place during Friday, Saturday or Sunday within the boundaries of the participating municipality. Other days could not be 
chosen because of vocational or educational obligations of the young drivers. In addition, most driver coaches involved had training duties that withheld them from providing the DX-program during other days of the week.

In general, the program aims to support young drivers during the most dangerous phase of their driving career and thereby to prevent them from getting involved in accidents. More specifically, the aim of the DX-program is to enable young drivers to make responsible decisions and develop positive attitudes for four levels of the driving task: (1) combining life level and work tasks with driving; (2) planning and navigation; (3) participating in different traffic situations; and (4) handling the vehicle.

The design principles of the DX-program are drawn from different sources of research. First, throughout the program, it is emphasized that driving style is affected by decisions on higher level tasks [3]. These include life tasks, e.g., socializing with peers, and strategic tasks, e.g., route decisions. Second, in the DX-program, it is emphasized that drivers need to reflect on their own decisions, actions and consequences regarding driving. Third, in line with their underdeveloped calibrating skills [20], young drivers are supported to maintain a safe balance between their own level of proficiency and the complexity of the traffic situations they engage in. Fourth, as the ultimate goal of the coaching program is improvement of driving quality, coaches are encouraged to address five inter-related criteria of driving performance [21]: (1) driving safely; (2) facilitating the traffic flow; (3) consideration with other road users' interests; (4) smooth vehicle control; (5) environmentally-responsible driving.

As part of the program, participants complete two web-based assessments a week before the start of the coaching day: the DRA (driver risk assessment) and the DSA (driver self-assessment). These assessments result in individual driver profiles, which are used to determine personalized learning goals at the start of the day.

The actual driver coaching day consists of three parts:

(1) a coached trip, of which the main objective is to deliver feedback to the drivers about their driving performance;

(2) track experiences, of which the main objective is for participants to experience the limits of their skills in vehicle control and to share these experiences with other participants. In line with research findings, the emphasis is not on skills to get out of a skid, but instead, in anticipation and not getting into any emergency situation [22];

(3) group discussion, of which the main objective is to stimulate recognition of potential risk factors in everyday driving situations, such as alcohol use and speed choice.

In this study, attention was focused on the entry characteristics of participating young drivers, which make up the conditions under which driver coaches deliver their coaching. The following research questions were addressed:

(1) What are the driving characteristics of young drivers enrolled in the DX-program (DX-participants) in terms of their driving history, their personal risk factors and their self-perceptions regarding driving performance? Do DX-participants differ from the average young Dutch driver on these driving characteristics?

(2) Are there any recognizable sub groups of DX-participants that differ from each other in terms of driving characteristics?

(3) How are participants motivated to take part in the DX-program? How does the type of motivation (intrinsic, extrinsic motivation) relate to driving characteristics?

\section{Method}

\subsection{Data Collection}

Most of the data were collected within the structure of the DX-program, which included online 
assessments as preparation for the coaching day. Data from the DRA and DSA were used to investigate the research questions. The DRA is a 119 item web-based questionnaire regarding the driver's history and behavioral risk factors. Driving history pertains to years of driving experience, mileage, types of traffic situations to which the driver is exposed, the number of active and passive accidents he was involved in during the past year and the number of fines received the past year. Questions regarding behavioral risk factors pertain to speed choice, lane preference on motorways, alcohol use and driving, anger towards other participants, distraction and fatigue. Most of the questions are Likert-type items.

The DSA is a web-based questionnaire consisting of 45 illustrated questions. It comprises a self-assessment of driving performance addressing the five performance criteria of driving described above. Each question is accompanied by a picture, showing the essential features of the traffic situation to which the question refers. Participants respond by using a four-point Likert-scale.

To assess young drivers' motives for participation, a translated version of the SIMS (Situational Motivation Scale) [23], a 16-item questionnaire, was administered to a sub sample of 174 participants on seven randomly chosen coaching days. This questionnaire was chosen because we had a limited time frame available, i.e., $15 \mathrm{~min}$ before the start of the coaching day. We needed to collect participants' motives just before they were going to start the program. Despite its limited length, the SIMS is a highly valid and reliable short questionnaire, which has proven to be applicable across different educational contexts and school subjects. In addition, it proved to be predictive for scores on more laborious alternative instruments [23]. The questionnaire results in scores for amotivation, extrinsic motivation and intrinsic motivation.

\subsection{Participants}

Data from young drivers enrolled on the DX-coaching program (referred to as "DX-group") were used. The DX-group $(n=3,117)$ participated in a total of 110 training groups, distributed across 66 municipalities.

The training programs involved took place in the period between August 2010 and November 2012, and enrolled 1,651 male and 1,466 female participants. The participants, aged between 18 and 24 years, had held their driving license for about one year. Their average mileage amounted to $7,274 \mathrm{~km}$, which is somewhat less than the mileage of the average Dutch young driver. The sub sample of 174 participants was representative for the whole DX-group in terms of the background variables described above.

To enable comparison with a reference group of young drivers (referred to as "YD-Ref group"), several analyses were performed on a database containing data from a large-scale survey that used representative samples of the Dutch population. This survey had been carried out almost yearly since 1990 [24] until 2005. For purposes of comparison, only the data from 2005 were used $(n=345)$, since traffic safety figures had changed considerably since 1990 .

\section{Results}

Table 1 shows the average number of accidents per one million kilometers. Since the data concerned frequency data on a fixed number of kilometers that were skewed to the right, a Poisson model was appropriate for modeling the active accident rates (driver at fault). The parameter differentiating the

Table 1 Mileage and average number of accidents per million kilometers.

\begin{tabular}{lllll}
\hline Group and age & Mileage & Active accidents & Passive accidents & Fines \\
\hline DX-group $(n=2,060)$ & 7,274 & 22.0 & 11.0 & 71.7 \\
YD-Ref group $(n=345)$ & 9,785 & 21.9 & 11.4 & 48.6 \\
\hline
\end{tabular}


Table 2 Self-reported behavior regarding risk factors.

\begin{tabular}{|c|c|c|c|c|}
\hline \multirow[b]{2}{*}{ Subscale DRA (driver risk assessment) } & \multicolumn{2}{|c|}{ DX-group $(n=2,060)$} & \multicolumn{2}{|c|}{ YD-Ref group $(n=345)$} \\
\hline & $\mathrm{M}($ mean) & $\begin{array}{l}\text { SD (standard } \\
\text { deviation) }\end{array}$ & M & SD \\
\hline Exposure to various risky traffic situations (five items, $\alpha^{* *}=0.78$ ) & $0.52 *$ & 0.22 & - & - \\
\hline Extensive alcohol use (two items, $\alpha=0.66$ ) & 0.38 & 0.23 & - & - \\
\hline Adversary alcohol strategies (11 items, $\alpha=0.93$ ) & 0.06 & 0.18 & - & - \\
\hline Concentration loss (13 items, $\alpha=0.81$ ) & 0.10 & 0.08 & - & - \\
\hline Seriously angry towards other road users (two items, $\alpha=0.51$ ) & 0.03 & 0.14 & 0.01 & 0.13 \\
\hline Irritated towards others (four items, $\alpha=0.63$ ) & 0.19 & 0.27 & 0.13 & 0.23 \\
\hline Withholds anger towards others (four items, $\alpha=0.59$ ) & 0.57 & 0.30 & 0.43 & 0.26 \\
\hline Stays calm towards others (two items, $\alpha=0.48$ ) & 0.74 & 0.35 & - & - \\
\hline Violation speed limits under various circumstances (nine items, $\alpha=0.92$ ) & 0.14 & 0.13 & - & - \\
\hline $\begin{array}{l}\text { Violation speed limits under favorable circumstances (three items, } \alpha= \\
0.65 \text { ) }\end{array}$ & 0.23 & 0.17 & 0.20 & 0.19 \\
\hline Driving on outer lanes (five items, $\alpha=0.75$ ) & 0.33 & 0.24 & - & - \\
\hline Fatigue during driving (five items, $\alpha=0.70$ ) & 0.09 & 0.10 & - & - \\
\hline
\end{tabular}

*0.0 0.16: rarely; 0.17 0.33: occasionally; 0.34 0.50: sometimes; 0.51 0.67: rather often; 0.68 0.84: very often; $0.85 \sim 1.0:$ most of the times; $\alpha^{* *}=$ coefficient Cronbach's alpha for internal consistency of the respective subscales.

averages in the DX-group and the YD-Ref group was tested using chi-square $\left(\chi^{2}\right)$ distribution with $1 \mathrm{df}$ (degree of freedom). The observed value did not differ significantly from $\left(\chi^{2}=0.06, d f=1, p=0.86\right)$. The two groups did not differ in their active accident risk.

Similar results were found for the passive accidents rate (driver not at fault). The two young driver groups did not differ significantly $\left(\chi^{2}=0.06, d f=1, p=0.06\right)$. Finally, the DX-group had a significantly higher fine rate than the YD-Ref group $\left(\chi^{2}=2,158, d f=1, p<\right.$ 0.001).

Table 2 shows results regarding behavioral risk factors. DX-participants reported that they rather often drive in risky traffic situations: during rush hour and weekend nights, on roads outside built-up areas and in town centers. In addition, they reported that they sometimes extensively use alcohol (mean: 0.38). However, they reported that they seldom combine extensive alcohol use with driving. This is reflected by the low score on the scale use of "adversary alcohol strategies" (mean: 0.06), referring to questions about adversary strategies to minimize the effects of alcohol once participants had taken alcohol, e.g., drink a cup of strong coffee before driving home.

A next risk factor, loss of concentration, rarely occurred to DX-participants (mean: 0.10). This scale referred to unconscious and distracted driving (e.g., cell phone use). The anger subscales referred to the driver's reaction on other road users' violations or deviating driving behavior. In terms of anger, DX-participants very often reacted calmly (mean: 0.74) but also rather often with withheld anger (mean: 0.57 ). Irritated reactions towards other participants occurred occasionally (mean: 0.19 ). Seriously angry reactions occurred rarely (mean: 0.03).

Comparisons of mean scores between the young driver reference group and the DX-group were made using $t$-tests for independent samples. These $t$-tests yield $t$-values which indicate a significant difference when the values are above 1.96 or below -1.96. It appeared that average young drivers reacted less frequently with irritation $(t=4.4, d f=2,992, p<$ $0.001)$, withheld anger $(t=9.2, d f=2,992, p<0.001)$ and serious anger $(t=2.5, d f=2,992, p<0.05)$ than the DX-participants.

A fourth risk factor pertained to speed choice and lane preference. On average, DX-participants claimed that they rarely violate the limits under average circumstances (mean: 0.14) and occasionally under favorable circumstances (mean: 0.23). DX-articipants reported that they sometimes prefer to drive on the outer lanes on the motorways (mean: 0.33). Finally, 
on average, DX-articipants rarely experienced fatigue while driving (mean: 0.09).

Table 3 shows results for the driver self-assessment. The first scale consisted of 14 items addressing errors that affect traffic safety (e.g., following too close), traffic flow (e.g., causing others to wait) and vehicle control (e.g., errors when using gears). On average, DX-articipants reported that they occasionally commit errors (mean: 0.18) that affect these criteria.

The second scale, "driving in a hurry" referred to the tendency to drive faster than the speed limits and to get irritated by those who drive slower than that. DX drivers reported that they sometimes drive in a hurry (mean: 0.44). The overall scale "perceived own driving proficiency” (45 items) covers the degree to which the driver reported a safe, flow-aiding, social, controlled and environmentally considerate way of driving. On average, DX drivers reported that they often show this driving behavior (mean: 0.74).

One hundred and seventy-four participants reported about their motives to participate through the SIMS questionnaire. The four-factor structure as found by Guay et al. [23] could be replicated after employment of a principal factor analyses. Also, the resulting subscales showed satisfactory internal consistencies (Table 4). Turning to the results on the SIMS, on average, the participants took part out of rather strong intrinsic motives (Table 4, items referred to statements as "it seems interesting", "it seems fun" and "it was my own decision”). Also, identified regulation, in the form of internalized motives offered from outside, was reported (e.g., "it gives a good feeling”, "it is for my own good” and “it is important to learn”). To a far lesser degree, participants reported external regulation in the form of conformation to outside pressure ("I had no choice”, "I had the feeling” and "I had to”). To a little higher degree, participants reported unclear motives that reflect amotivation ("I don't know if I go on with this" and "I don't know why I participate”).

Correlations between the scores on the four motivation scales and the reported driving characteristics are presented in Table 5. To the extent that participants scored higher on the internalized form of extrinsic motivation, they tended to drive less hurried, violate speed limits less frequently, drive less frequently on outer lanes and report in general a higher perceived driving proficiency. Opposite relationships for proficiency self-image, speed violations and hurried driving were observed for the degree in which participants show amotivation. Intrinsic motivation correlated positively with driving proficiency and negatively with committing driving errors. External regulation, which comes with conformation to outside pressure, correlated positively with committing of driving errors and negatively with overall perceived driving proficiency.

Table 3 Driving proficiency reported by the DX-group $(n=2,924)$ on the driver self-assessment.

\begin{tabular}{lll}
\hline Subscale DSA (driver self-assessment) & M & SD \\
\hline Committing driving errors (14 items, $\alpha=0.77)$ & 0.18 & 0.10 \\
Driving in a hurry (six items, $\alpha=0.74)$ & 0.44 & 0.17 \\
Perceived own driving proficiency* $(45$ items, $\alpha=0.83)$ & 0.74 & 0.81
\end{tabular}

0.0 0.16: rarely; 0.17 0.33: occasionally; 0.34 0.50: sometimes; 0.51 0.67: rather often; 0.68 0.84: very often; 0.85 1.0: most of the times; *negatively formulated items reversed.

Table 4 Motivation of a representative sub sample of participants $(n=174)$.

\begin{tabular}{lll}
\hline SIMS (subscale situational motivation scale) & M & SD \\
\hline Intrinsic motivation (four items, $\alpha=0.79$ ) & 5.67 & 0.82 \\
Identified regulation: internalized motives offered from outside (four items, $\alpha=0.81$ ) & 5.10 & 0.99 \\
External regulation: conforming to outside pressure (five items. $\alpha=0.79$ ) & 2.31 & 1.14 \\
Amotivation (three items, $\alpha=0.63$ ) & 2.73 & 1.07 \\
\hline
\end{tabular}

Likert-scale per item: 1 = does not apply to me; 4 = applies reasonably to me; 7 = applies totally to me. 
Table 5 Correlations between motivation and some driving characteristics.

\begin{tabular}{lllll}
\hline & \multirow{2}{*}{ Amotivation } & $\begin{array}{l}\text { External regulation: } \\
\text { outside pressure }\end{array}$ & $\begin{array}{l}\text { Identified regulation: } \\
\text { internalized motives }\end{array}$ & $\begin{array}{l}\text { Intrinsic } \\
\text { motivation }\end{array}$ \\
\hline Committing driving errors & 0.15 & $0.19^{*}$ & 0.09 & $-0.19^{*}$ \\
Driving in a hurry & $0.19^{*}$ & 0.04 & $-0.29^{* *}$ & -0.12 \\
Perceived own driving proficiency & $-0.32^{* *}$ & $-0.27^{* *}$ & $0.26^{* *}$ & $0.32^{* *}$ \\
Violation speed limits under various circumstances & $0.19^{*}$ & 0.08 & $-0.37^{* *}$ & -0.13 \\
Driving on outer lanes & 0.11 & 0.00 & $-0.24^{* *}$ & -0.03 \\
\hline
\end{tabular}

$* p<0.05 ; * *<<0.01$.

Finally, hierarchical cluster analyses on the driving characteristics identified four sharply distinct clusters of participants. The biggest cluster reflected the average DX-participant (71\%), as described above. One small cluster (1\%) represented "fast and aggressive" drivers who found themselves rather often on outer lanes (mean: 0.60 ) and who drove in a hurry most of the times (0.84), and reported more errors than drivers in the other clusters, but who, at the same time, did not consider themselves as erratic drivers (0.26). Both their relative active accident risk (61 accidents per one million kilometers) and their number of fines (120 fines per one million kilometers) were two times higher than those of the average DX-participant. Another cluster represented "erratic and fast" drivers (4\%), who reported that they sometimes committed driving errors (mean: 0.37). Their relative active accident risk (54 accidents per one million kilometers) and number of fines (139 fines per one million kilometers) were comparable to that of the "fast and aggressive drivers". A final cluster represented "rule following calm drivers" (25\%). They reported that they seldom violated speed limits (mean: 0.07) nor lost concentration during driving (0.08) and that they reacted calmly towards deviating drivers (0.86). All reported differences were tested by means of analyses of variance. These analyses yield $F$-values, which indicate whether pre-defined groups differ from each other. The difference between the clusters was highly significant, with $F$-values ranging between 3.7 (lowest significant value for active accident risk) and 1,130 (highest significant value for hurried driving). The median
$F$-value for the differences between the clusters was 38.

For the subset of DX-participants who completed the SIMS, a comparison of the driving characteristic clusters could be made for two clusters, the "rule following calm drivers" versus the average DX-participant. It turned out that the first group reported higher levels of intrinsic motivation (means 5.9 vs. $5.6 ; t=2.0 ; d f=129, p=0.04$ ) and identified regulation (means 5.7 vs. $5.0 ; t=3.6, d f=129, p<$ $0.01)$ than the second group, whereas the groups did not differ on external regulation. Finally, the rule followers showed significantly lower levels of amotivation than the average DX-participant (means 2.3 vs. $2.8 ; t=-2.3, d f=128, p<0.05)$.

\section{Discussion}

\subsection{Summary of Findings}

From research on teaching, it is known that group heterogeneity is one of the most challenging factors for teachers to deal with. Given the context of the second phase training program under study, referred to as the DX, a one day program enrolling participants unknown to the coaches, heterogeneity was expected to be an issue for driver coaches. This study has shed some light on the entry characteristics of recently young licensed drivers who chose to participate in the DX-program.

As part of the DX-program, participants went through assessments that yielded a picture of their individual driving styles and accident, and fine history. Driver coaches were encouraged to use the assessment reports in order to adapt the coaching to the individual 
participants' needs.

The online assessments yielded rich data that enabled the current study regarding driver entry characteristics to be carried out. In the period between June 2010 and November 2012, over 3,000 participants enrolled in the DX-program. On a smaller scale, we collected data about young drivers' motivation to participate in the DX-program amongst 174 young drivers.

In the current study, participants of the DX-program were compared with average young drivers. In addition, analyses related to the group heterogeneity were carried out. The following behavioral factors were involved: fatigue, driving anger, concentration and distraction, speed choice, lane choice, exposure, alcohol use and driving. These factors have proven to be important to explain accident involvement. Most of the assessed factors are considered to originate in the personal life style of the driver. During the DX-program, participants commit themselves to personal learning goals which address the combination of lifestyle and driving. These goals reflect the highest level of the GDE (Goals for Education) matrix [3].

Looking at their entry characteristics, the following conclusions can be drawn regarding DX-participants. Looking at the driving history, it appears that DX-participants have an equal accident risk when compared with average young drivers. Their number of fines per one million kilometers appeared significantly higher than average. In general, DX-participants reported that they rather often drive in risky traffic situations, including driving during rush hours and weekend nights on roads outside built-up areas and in town centers.

Regarding the self-perceptions, DX-participants reported that they often drive safely, flow-aiding, socially and environmentally considerate, and controlled. They reported that they only occasionally commit errors that affect traffic safety and traffic flow. In addition, they reported that they rarely violate the speed limits and sometimes prefer to drive on the outer lanes on the motorways. So, all in all, DX-participants hold a positive self-image regarding their own driving proficiency.

Regarding their personal risk factors, the DX-participants reported that they seldom combine alcohol use with driving. Loss of concentration rarely occurred to DX-participants, as was the case for expression of irritation or aggression towards other participants. On the contrary, on average, DX-participants very often reacted calmly towards others. DX-participants rarely experienced fatigue while driving.

Despite their positive self-image, DX-participants showed a somewhat less favorable driving style than the average young (Dutch) driver. In terms of their relative accident risk, they were comparable to the average young driver. However, their number of fines was higher, they reported more frequently irritation towards other drivers. Although the absolute reported frequency was relatively low, they committed more driving errors and speed violations than average young drivers.

Looking within the group of DX-participants, it became clear that the coaching program attracted young drivers with different driving styles. Next to a large group “average” DX-participants, three other groups could be discerned. The largest of them represented drivers, who always obey speed limits, showed low accident rates and generally stayed calm towards other road users. Next, there were two relatively small groups that had very unfavorable driving characteristics. They had been more frequently involved in crashes than average, collected many more fines, and reported more often unfavorable driving behaviors regarding speed choice and aggression. These two latter groups differed in their self-image. One group reported own erratic behavior, while the other group hardly did. So, all in all, the group heterogeneity in terms of past driving performance and driving characteristics was 
considerable within the analyzed period of two years.

With regard to their motivation to participate, participants showed either strong intrinsic motives or internalized motives offered from outside to take part. Both intrinsic motivation and identified regulation made up positive conditions for subsequent learning. However, some participants started from unclear motives or from outside pressure (e.g., forced by parents). We found that unclear motives paralleled with unfavorable driving styles, whereas intrinsic motivation or internalized motives were related to more favorable driving styles.

\subsection{Methodological Limitations}

Some methodological limitations need to be mentioned. The first two of them represent threats to the generalizability of the research findings. First, the data from the young driver reference group, against which the DX-group was contrasted, were taken from 2005. This reference group may not be equivalent to the DX-group, due to a different time frame. In the period of seven years, some traffic safety issues may have changed, for instance, regarding distraction by multi media. The use of social media running on cell phones and tablets inside cars has introduced invasive kinds of distraction. On the other hand, risk factors such as anger, fatigue and speeding, have not changed since 2005 and remain applicable in the current time frame.

Second, the samples used are in fact samples of convenience, which may have resulted in possible effects of self-selection. However, at least, the results show demographic comparability of the DX-sample with the sample of average young drivers. In addition, the results show that possible self-selection has not resulted in inclusion of only highly motivated, rule following participants, who already show favorable driving styles, as could be expected from a field study [25].

Third, participant motivation was measured by means of questionnaires. Instead, we could have asked open-ended questions in in-depth interviews with respect to the motives that had led participants to the DX-program. We did not choose to do so for practical reasons. However, the SIMS proved to be a very reliable and valid measure for situation specific motivation that showed high correlation with scores on in-depth measures in earlier studies [23].

\subsection{Practical Issues}

A first practical issue relates to the question whether the program has attracted the intended target group. The idea was to attract not only the well-raised, highly-educated and wealthy young drivers, as some policy makers thought would happen, but instead a representative sample of young drivers. The latter turned out to be the case, as was demonstrated in the appearance of four distinct clusters of drivers with different driving characteristics.

A second practical issue relates the group composition for the coached drives. How should driver coaches compose their small groups in which they set off for the coached drives? In each car, three young drivers changed roles between being the driver and being the provider of feedback to a peer participant. A question would be whether groups should be more homogeneous or heterogeneous in terms of driving characteristics and motivation to learn. In general, the quality of dialogues is expected to be richer in heterogeneously composed groups $[26,27]$. On the other hand, a reason to opt for homogeneous groups is that heterogeneous groups ask for a differentiated approach on part of the coach, which leads to a heavier task burden [28]. Regarding group composition, a measure that was taken during the DX-program was to prevent close friends to get into the same car to prevent restraint in giving honest and constructive peer feedback.

A third practical issue pertained to the availability of the program for all young drivers. Although there are similar programs all over the Dutch country, just a fraction of the population of young drivers is actually 
involved. It would have been preferable that all licensed drivers were involved in the second phase driver coaching program. Due to budget limitations, this turned out to be infeasible. To counter this problem, the pre and post license phases of driver training are increasingly being integrated in the Netherlands. Building on the experiences of the DX-program, driving schools are beginning to offer a two-phase program in which learner drivers buy in. Approximately half a year after licensing, a group of young drivers is invited to enroll in the second phase day, which is a regular part of their pre-ordered and pre-paid programs.

\subsection{Considerations Regarding Educational Design and Research}

To conclude this paper, some considerations can be made regarding educational design of driver training and coaching. The question of group heterogeneity is just one of the variables that need to be addressed in research into conditions and characteristics of effective instructional design.

The prevalent research message that educational interventions have little effect on traffic safety [29] is increasingly contradicted by new research findings. Isler et al. [8] demonstrated that it is possible to counteract unsafe driving styles using sophisticated educational designs that address higher order skills of the driver (learner).

One of the objections against the conclusion of non-effectiveness of driver training can be that the studies also included training programs which reflect a restricted view of driving competence, mostly defined as vehicle handling and knowledge of traffic rules. In general, educational goals for the 21st century have moved away from taxonomies of unrelated superficial knowledge and reproductive skills. Instead, more emphasis is put on meaningful learning of higher order skills [30]. Likewise, the introduction of the GDE-matrix has changed the conception of driving competence. Driving a car is now seen as a complex task that is intertwined with daily life tasks and involves strategic skills such as: aligning life-level goals with travel purposes, reflecting on the effects of own driving behavior for traffic safety, planning and adjusting the route according to travel purposes. The changed learning outcomes ask for different educational designs, as recognized by several authors [31].

Apart from the possibly restricted notion of driving in the past, it stands to reason that the absence of effects of driving instruction could be attributed to poor instructional design and unpreparedness on the part of the driver trainers and coaches. Following the fundamental tenet of modern learning theory that different kinds of learning goals require different approaches to instruction, a new generation of training programs is to be developed. Research from cognitive psychology has increased our understanding of the nature of competent performance in a wide variety of areas [32]. Within the educational research field, a knowledge base has emerged. It is time to apply and extend this knowledge in the field of driver training and coaching. We would therefore urge for a next step in research regarding driver learning in which instructional designs are introduced, which are informed both by traffic psychology, educational psychology and insights from educational research. Until now, in-depth knowledge from educational research sources has hardly been used nor referred to in traffic safety journals. Inclusion of concepts and methods originating from educational psychology $[33,34]$ helps to gain more insight into the quality of the educational design, the subsequent learning process and the effects on driving competence.

The role of calibration skill, self-regulation, motivation and self-reflection, as referred to in the introduction of this paper, will be crucial to explain differences in learning gains [35] and in safe driving [20, 36]. Questions to be addressed could be: how accurately do young drivers estimate their own driving proficiency? How accurately can they set 
improvement goals that match their actual needs, based on individual driving style reports? How accurately can they monitor their progress towards stated goals? How adequately do they adjust their learning strategies [37]? How are motivation to learn and self-regulation related during driver learning? Are these skills amenable for change in a driver learning context?

Investigating these questions requires intrusive forms of data collection, like analyses of the dialogues and interactions among learners and coaches [38], analyses of thinking aloud protocols during driving tasks, analyses of the types of expert and peer feedback that are provided, and analyses of how feedback is used by learners.

Finally, it cannot be expected that a single one day intervention, which comprises the DX-program after all, will have long-term effects. Probably, a combination of interventions, which put driving safety permanently on (young) drivers' learning agendas, is to be preferred above short-term interventions. In the end, the question will be whether the combination of educational interventions results into sustainable learning gains, in terms of improved driving competence and eventually in terms of safer driving. For practical purposes, it is important to sort out which educational design characteristics contribute to these effects [39], directly or indirectly.

\section{References}

[1] Elander, J., West, R., and French, D. 1993. "Behavioural Correlates of Individual Differences in Road Traffic Crash Risk: An Examination of Methods and Findings." Psychological Bulletin 113 (2): 279-94.

[2] Helman, S., Grayson, G., and Parkes, A. M. 2010. How Can We Produce Safer New Drivers? A Review of the Effects of Experience, Training and Limiting Exposure on the Collision Risk of New Drivers. TRL (Transport Research Laboratory) insight report INS005.

[3] Hatakka, M., Keskinen, E., Gregersen, N. P., Glad, A. and Hernetkoski, K. 2002. "From Control of the Vehicle to Personal Self-control: Broadening The Perspectives to Driver Education" Transportation Research Part F 5: 201-15.
[4] Mayhew, D. R., and Simpson, H. M. 2002. "The Safety Value of Driver Education and Training." Injury Prevention 8: 3-8.

[5] Beanland, V., Goode, N., Salmon, P. M., and Lenné, M. G. 2013. "Is There a Case for Driver Training? A Review of the Efficacy of Pre- and Post-license Driver Training." Safety Science 51 (1): 127-37.

[6] Gatscha, M., and Brandstaetter, C. 2008. "Evaluation der Zweiten Ausbildungsphase in Österreich (Evaluation of the Second Phase System in Austria)." Presented at Research into the Traffic System Booklet 173. Austrian Federal Ministry of Transport, Innovation and Technology, Vienna, Austria.

[7] Isler, R. B., Starkey, N. J., and Sheppard, P. 2011. "Effects of Higher-Order Driving Skill Training on Young, Inexperienced Drivers' On-road Driving Performance." Accident Analysis Prevention 43 (5): 1818-27.

[8] Isler, R. B., Starkey, N. J., and Williamson, A. R. 2009. "Video-Based Road Commentary Training Improves Hazard Perception of Young Drivers in a Dual Task." Accident Analysis Prevention 41 (3): 445-52.

[9] Bartl, G., Sanders, N., Reikl, A., Schulte, K., Keskinen, E., and Whitmore, J. 2010. HERMES (High Impact Approach for Enhancing Road Safety through More Effective Communication Skills) in the Context of Category B Driver Training. EU HERMES project final report.

[10] Winne, P. H., and Hadwin, A. F. 1998. "Studying as Self-regulated Learning." In Metacognition in Educational Theory and Practice, edited by Hacker, D. J., Dunlosky, J., and Graesser, A. C. Hillsdale: Erlbaum, 277-304.

[11] Boekaerts, M. 1999. "Self-Regulated Learning: Where We Are Today." International Journal of Educational Research 31 (6): 44557.

[12] Boekaerts, M., and Cascallar, E. 2006. "How Far Have We Moved toward the Integration of Theory and Practice in Self-regulation?" Educational Psychology Review 18 (3): 199-210.

[13] Berliner, D. C. 2001. "Learning about and Learning from Expert Teachers." International Journal of Educational Research 35 (5): 463-82.

[14] Bartl, G., Gregersen, N. P., and Sanders, N. 2005. EU MERIT Project: Minimum Requirements for Driving Instructor Training. Vienna: Institut Gute Fahrt.

[15] Deci, E. L., and Ryan, R. M. 2000. "The 'What' and 'Why' of Goal Pursuits: Human Needs and the Self-determination of Behavior." Psychological Inquiry 11 (4): 227-68.

[16] Butler, D. L., and Winne, P. H. 1995. "Feedback and Self-regulated Learning: A Theoretical Synthesis." 
Review of Educational Research 65: 245-81.

[17] Pintrich, P. R., and de Groot, E. V. 1990. "Motivational and Self-regulated Learning Components of Classroom Academic Performance." Journal of Educational Psychology 82 (1): 33-40.

[18] Zimmerman, B. J. 1990. "Self-regulated Learning and Academic Achievement: An Overview." Educational Psychology 25 (1): 3-17.

[19] Sanders, N., and Keskinnen, E., eds. 2004. EU NovEV Project: Evaluation of Post-Licence Training Schemes for Novice Drivers. Final report, International Commission of Driver Testing Authorities CIECA (Commission Internatinale des Examens de Conduite Automobile), Rijswijk, The Netherlands.

[20] Fuller, R. 2005. "Towards a General Theory of Driver Behaviour." Accident Analysis and Prevention 37 (3): 461-72.

[21] Roelofs, E. C., Onna, M., and van Vissers, J. 2010. "Development of the Driver Performance Assessment: Informing Learner Drivers of Their Driving Progress." In Driver Behavior and Training, edited by Dorn, L. Vol. IV. Hampshire: Ashgate Publishing Limited, 37-50.

[22] Katila, A., Keskinen, E., Hatakka, M., and Laapotti, S. 2004. "Does Increased Confidence among Novice Drivers Imply a Decrease in Safety? The Effects of Skid Training on Slippery Road Accidents." Accident Analysis \& Prevention 36 (4): 543-50.

[23] Guay, F., Vallerand, R. J., and Blanchard, C. 2000. "On the Assessment of Situational Intrinsic and Extrinsic Motivation: The Situational Motivation Scale (SIMS)." Motivation and Emotion 24 (3): 175-213.

[24] Eversdijk, J. J. C., Bos, E. K., Jessurun, M., and Vissers, J. A. M. M. 2000. PROV 1999 Periodiek Regionaal Onderzoek Verkeersveiligheid (Periodic Dutch Regional Research into Traffic Safety). Report number: TT00-66, Traffic Test BV, Veenendaal. (in Dutch)

[25] Cook, T. D., and Campbell, D. T. 1979. Quasi-Experimentation: Design and Analysis Issues for Field Settings. Boston: Houghton Mifflin.

[26] Johnson, W. W., and Johnson, R. T. 2009. "An Educational Psychology Success Story: Social Interdependence Theory and Cooperative Learning." Educational Researcher 38 (5): 365-79.

[27] Slavin, R. E. 1991. "Synthesis of Research on
Cooperative Learning." Educational Leadership 48 (February): 71-82.

[28] Roelofs, E., and Veenman, S. 2000. "Classroom Heterogeneity and the Use of Instructional Time in Dutch Secondary Schools." Journal of Classroom Interaction 35 (2): $15-24$.

[29] Christie, R. 2001. The Effectiveness of Driver Training: $A$ Review of the Literature, RACV (Royal Automobile Club of Victoria), Literature report No. 01/03, Noble Park, Victoria.

[30] Marzano, R. J., and Heflebower, T. 2012. Teaching and Assessing 21st Century Skills. Bloomington: Marzano Research Laboratory.

[31] Peräaho, M., Keskinen, E., and Hatakka, M. 2003. Driver Competence in a Hierarchical Perspective: Implications for Driver Education. Turku: Turku University, Traffic Reseacrh.

[32] Bransford, J. D., Brown, A., and Cocking, R. R. 1999. How People Learn: Brain, Mind, Experience, and School. Washington, D.C.: National Academy Press.

[33] Vermunt, J. D., and Verloop, N. 1999. "Congruence and Friction between Learning and Teaching." Learning and Instruction 9 (3): 257-80.

[34] Vygotsky, L. S. 1978. Mind in Society: The Development of Higher Psychological Processes. Cambridge: Harvard University Press.

[35] Boekaerts, M., and Rozendaal, J. S. 2010. "Using Multiple Calibration Indices in Order to Capture the Complex Picture of What Affects Students' Accuracy of Feeling of Confidence." Learning and Instruction 20 (5): 372-82

[36] De Craen, S. 2010. "The X-Factor: A Longitudinal Study of Calibration in Young Novice Drivers." Doctoral dissertation. Leidschendam: SWOV, Institute of Road Safety Research.

[37] Hadwin, A. F., and Webster, E. A. 2013. "Calibration in Goal Setting: Examining the Nature of Judgments of Confidence." Learning and Instruction 24: 37-47.

[38] Rismark, M., and Sølvberg, A. M. 2007. "Effective Dialogues in Driver Education." Accident Analysis and Prevention 39 (3): 600-5.

[39] Hattie, J. 2009. Visible Learning: A Synthesis of over 800 Meta-analyses Relating to Achievement. London: Routledge. 